\title{
Optimality of the Friedman rule in overlapping generations model with spatial separation
}

\author{
Joseph H. Haslag and Antoine Martin *
}

June 2003

\begin{abstract}
Recent papers suggest that when intermediation is analyzed seriously, the Friedman rule does not maximize social welfare in overlapping generations model in which money is valued because of spatial separation and limited communication. These papers emphasize a trade-off between productive efficiency and risk sharing. We show financial intermediation or a trade-off between productive efficiency and risk sharing are neither necessary nor sufficient for that result. We give conditions under which the Friedman rule maximizes social welfare and show any feasible allocation such that money grows faster than the Friedman rule is Pareto dominated by a feasible allocation with the Friedman rule. The key to the results is the ability to make intergenerational transfers.
\end{abstract}

*Economics Department, University of Missouri-Columbia and Research Department, Federal Reserve Bank of Kansas City, respectively. We thank Scott Freeman, Jordan Rappaport, Gordon Sellon, and $\mathrm{Pu}$ Shen for useful comments. All remaining errors are our own. The views expressed here are those of the authors and not necessarily those of the Federal Reserve Bank of Kansas City or the Federal Reserve System. 


\section{Introduction}

The question of the optimum quantity of money is of great importance to monetary theory. It is also a vexing question because of the disparity between theory and practice. Theory has shown the Friedman rule to be optimal in many different environments and under many different assumptions (see, for example, Kimbrough 1986; Chari, Christiano, and Kehoe 1996; Correia and Teles 1996). Yet, in practice, no central bank (CB) states as its objective to implement the Friedman rule, and historical episodes in which deflation occurred and interest rates approached zero have often been considered very negative. ${ }^{1}$ A theory explaining why the Friedman rule might not be optimal would help resolve this disparity and would thus be of particular interest.

Several recent papers have tried to make a case against the Friedman rule. $^{2}$ These papers argue the Friedman rule does not maximize a social welfare function in overlapping generations model in which money is valued because of spatial separation and limited communication. This result is thought to arise because of the careful modelling of financial intermediation. ${ }^{3}$ In these models, some set of agents is randomly relocated. Relocated agents can only take cash with them and banks arise endogenously to help share the risk of relocation. These models exhibit a trade-off between productive efficiency and risk sharing. The banks' reserve-to-deposit ratio is a

\footnotetext{
${ }^{1}$ The Great Depression and Japan in the 1990s are two such episodes.

${ }^{2}$ See Paal and Smith (2000), Smith (2002 a and b). Similar results arise in other models of this class, such as in Schreft and Smith $(2002,2003)$ but are not emphasized there.

${ }^{3}$ Smith (2002b) writes, "As will be seen, when intermediation is analyzes seriously, the Friedman rule generally will not be optimal... ."
} 
function of the money growth rate which is set by the CB. If the CB follows the Friedman rule the consumption of movers and nonmovers is equalized. Movers are thus fully insured, but since the banks' reserves are very high, the rate of productive investment is very low. On the other hand, the $\mathrm{CB}$ could set a high rate of growth of the money supply. This high-money-growth-rate policy leads to high investment but also to an increase in the disparity of consumption between movers and nonmovers. ${ }^{4}$

We argue the case made against the Friedman rule in these models is a lot weaker than it seems. We show financial intermediation or a trade-off between productive efficiency and risk sharing are neither necessary nor sufficient for the Friedman rule not to maximize social welfare. Instead, this result arises because means of transferring resources from the initial old generation to the current and future generations are ruled out. We show the Friedman rule maximizes social welfare when mutually beneficial arrangements are allowed or if the CB can make loans. We also show any feasible allocation obtained if money grows faster than the Friedman rule is Pareto dominated by a feasible allocation obtained if the Friedman rule is followed.

The remainder of the paper proceeds as follows: Section 2 describes the environment. Section 3 shows that financial intermediation or a trade-off between productive efficiency and risk sharing are neither necessary nor sufficient for the Friedman rule to be sub-optimal. Section 4 highlights the importance of intergenerational transfers. Section 5 concludes.

\footnotetext{
${ }^{4}$ Paal and Smith (2000) write, "The optimal level of the nominal rate of interest in our economy is determined by trading off the benefits of bank liquidity provision (insurance) against higher rates of real growth."
} 


\section{The environment}

We consider the economy described in Schreft and Smith (2002). ${ }^{5}$ Only a succinct description of the economic environment is provided; the interested reader is referred to Schreft and Smith (2002) for more details.

Time is divided into an infinite number of identical increments and is indexed by $t=1,2 \ldots$. The world is divided into two spatially separated locations. Each location is populated by a continuum of agents of unit mass. Agents live for two periods and receive an endowment of $\omega$ units of the single consumption good when young and nothing when old. There also is an initial old generation whose members are endowed with an amount of cash $M_{0}$. Only old-age consumption is valued. Let $c_{t}$ denote old-age consumption of the members of the generation born at date $t$; their lifetime utility is given by $u\left(c_{t}\right)=\frac{c_{t}^{1-\rho}}{1-\rho}$, where $\rho \in(0,1)$.

After receiving their endowment and placing it into a bank, agents learn whether they must move to the other location or not. Let $\pi$ denote the probability that an individual will be relocated. We assume a law of large numbers holds so $\pi$ is also the measure of agents that are relocated. $\pi$ is the same on both islands so that moves across location are symmetric. Movers redeem their bank deposits in the form of money as this is the only way for

\footnotetext{
${ }^{5}$ The result that the Friedman rule does not maximize social welfare arises in many related environments. We choose this model for ease of exposition. Our results extend in a straightforward way to other environments such as those in Paal and Smith (2000), Smith (2002 a and b). Predecessors in this literature include Townsend's (1980) model with limited communication and extends through Bencivenga and Smith (1991) and Bhattacharya, Guzman, Huybens, and Smith (1997).
} 
them to acquire goods in the new location. In contrast, nonmovers redeem their deposits in the form of goods.

Goods deposited in the bank can be used to acquire money from old agents belonging to the previous generation or put into storage. Each unit of the consumption good put into storage at date $t$ yields $x>1$ units of the consumption good at date $t+1$, where $x$ is a known constant.

The CB can levy lump-sum taxes $\tau$ on the endowment of agents by collecting the tax in the form of money balances removed from the economy. In contrast, a lump-sum subsidy is received in the form of a money injection. In short, $\tau$ can be either positive or negative. The money supply evolves according to $M_{t+1}=\sigma M_{t}$ and $\sigma$ is chosen by the CB as will be explained below. Since we consider steady states, $p_{t+1}=\sigma p_{t}$.

\subsection{Bank behavior}

Agents deposit their entire after-tax/transfer endowments with a bank. The bank chooses a gross real return $d_{t}^{m}$ to pay to movers and $d_{t}^{n}$ to pay to nonmovers. In addition, the bank chooses values $m_{t}$ and $s_{t}$ standing for the real value of money balances and storage investment, respectively.

These choices must satisfy the bank's balance sheet constraint

$$
m_{t}+s_{t} \leq \omega-\tau
$$

Banks behave competitively, so they take as given the return on their investments. In particular, the return on real money balances is $p_{t} / p_{t+1}$. If $x>p_{t} / p_{t+1}$ banks will want to hold as little liquidity as possible since 
money is dominated in rate of return. If $x=p_{t} / p_{t+1}$, banks are indifferent between money and storage. In this case, we consider the limiting economy as $p_{t} / p_{t+1} \rightarrow x$.

Banks must have sufficient liquidity to meet the needs of movers. This is captured by the following expression,

$$
\pi d_{t}^{m}(\omega-\tau) \leq m_{t} \frac{1}{\sigma}
$$

A similar condition for nonmovers, who consume all the proceeds from the storage technology, is given by

$$
(1-\pi) d_{t}^{n}(\omega-\tau) \leq x s_{t}
$$

Banks maximize profits. Because of free entry banks choose, in equilibrium, their portfolio in a way that maximizes the expected utility of a representative depositor. After substitution, the bank's problem is written as

$$
\frac{(\omega-\tau)^{1-\rho}}{1-\rho}\left\{\pi d_{t}^{m}(\sigma)^{1-\rho}+(1-\pi) d_{t}^{n}(x)^{1-\rho}\right\}
$$

subject to equations 1,2 , and 3 .

The time subscript is dropped in what follows as we focus on steady-state allocations. Let $\gamma=\frac{m}{\omega-\tau}$ denote the bank's reserve-to-deposit ratio. Then, since equations 1, 2, and 3 hold with equality, the bank's objective function is to choose $\gamma$ to maximize

$$
\frac{(\omega-\tau)^{1-\rho}}{1-\rho}\left\{\pi^{\rho}\left[\frac{\gamma}{\sigma}\right]^{1-\rho}+(1-\pi)^{\rho}[(1-\gamma) x]^{1-\rho}\right\} .
$$

As shown in the appendix, the reserve-to-deposit ratio chosen by the bank increases as $\sigma$ decreases. Hence, as the rate of growth of the money supply 
approaches the Friedman rule, banks increase their holding of money which implies they invest less in the storage technology. Since the Friedman rule implies full insurance against the risk of being relocated, this is the sense in which there is a trade-off between efficiency and risk sharing.

\subsection{The optimum quantity of money}

As is usual in this class of models, steady-state social welfare is evaluated as the expected utility of a member of generation $t \geq 1$. The welfare of the initial old is ignored. It follows that the CB chooses $\sigma \geq 1 / x$ in order to maximize equation 5 subject to the government budget constraint. The Friedman rule corresponds to $\sigma=1 / x$. In this case, the rate of return of money is equal to the rate of return of storage. This definition is consistent with Friedman's (1969) dictum.

It is shown in the appendix that welfare is maximized at $\sigma=1$. We can summarize this result in the following proposition,

Proposition 1 The Friedman rule does not maximize social welfare. The maximizing rate of growth of the money supply is strictly greater than $1 / x$.

Schreft and Smith (2003) show the results of this section are unaffected when $x$ is a random variable, rather than a known constant. 


\section{The role of intermediation and the trade- off between efficiency and risk sharing}

This section shows financial intermediation or a trade-off between productive efficiency and risk sharing are neither necessary nor sufficient for the result that the Friedman rule does not maximize social welfare. To establish the fact that these features are not necessary, we consider slight variations of the benchmark model. In the first alternative model, financial intermediation plays no role. The second alternative model is a pure exchange economy, so there can be no trade-off between efficiency and risk sharing. Yet in both of these models, the Friedman rule does not maximize social welfare. To show that these features are not sufficient, we consider once again the benchmark model but assume the $\mathrm{CB}$ can make inter-period loans. In this case, the Friedman rule maximizes social welfare.

\subsection{Intermediation}

This section describes a world similar to the one presented above, but where intermediation plays no role. We show proposition 1 also holds in this economy.

Time is indexed by $t=1,2, \ldots$ and the world is divided in two spatially separated locations. Each location is populated with a continuum of agents of unit mass, who live for two periods. Agents receive an endowment $\omega$ of a location-specific good when young and nothing when old. Only oldage consumption is valued. There also is an initial old generation whose 
members are endowed with an amount of cash $M_{0}$. These agents gets utility from consumption of the endowment good received by the young who live on their island. Let $c_{h, t}$ and $c_{a, t}$ denote old-age consumption of home-location and away-location goods, respectively, of agents born at date $t \geq 1$. These agents have lifetime utility

$$
u\left(c_{h, t}, c_{a, t}\right)=\lambda^{\rho} \frac{c_{a, t}^{1-\rho}}{1-\rho}+(1-\lambda)^{\rho} \frac{c_{h, t}^{1-\rho}}{1-\rho}, \quad \rho, \lambda \in(0,1) .
$$

There is no uncertainty in this economy. After receiving their endowment, consumers can sell some goods to old agents who moved from the other location in exchange for money. They invest the remainder of their goods in a storage technology. Each unit of the location-specific good put into storage at date $t$ yields $x>1$ units of the same good at date $t+1$, where $x$ is a known constant. In old age, agents receive the return from their investments and consume it. Later during that period, they travel to the other location and can buy location-specific goods from young agents. Young agents cannot travel and old agents from one location never meet the old agents from the other location.

Clearly there is no scope for intermediation in this economy since all agents are identical and face no uncertainty. Monetary policy is conducted as in the previous section. The $\mathrm{CB}$ chooses the rate of growth of the money supply to maximize social welfare which is given by the utility of a member of generation $t \geq 1$. Let $m_{t}$ denote the real amount of money acquired by a consumer and $s_{t}$ the amount stored by that consumer,

$$
m_{t}+s_{t} \leq \omega-\tau
$$


Money can be used in the next period to acquire away-location goods.

$$
c_{a, t} \leq m_{t} \frac{1}{\sigma}=(\omega-\tau) \frac{\gamma}{\sigma}
$$

Home-location consumption can be no greater than the proceeds from storage.

$$
c_{h, t} \leq x s_{t}=(\omega-\tau)(1-\gamma) x
$$

Substituting these quantities into the agent's utility function yields

$$
\frac{(\omega-\tau)^{1-\rho}}{1-\rho}\left\{\lambda^{\rho}\left[\frac{\gamma}{\sigma}\right]^{1-\rho}+(1-\lambda)^{\rho}[(1-\gamma) x]^{1-\rho}\right\}
$$

which corresponds exactly to equation 5 whenever $\lambda=\pi$. It follows that proposition 1 also holds in the present environment. This can be summarized in the following proposition,

Proposition 2 Financial intermediation is not necessary for the result that the Friedman rule does not maximize social welfare.

\subsection{A pure exchange economy}

To show a trade-off between productive efficiency and risk sharing is not necessary for the result that the Friedman rule does not maximize social welfare, we establish that proposition 1 also holds in an economy without production.

Time is indexed by $t=1,2, \ldots$ and the world is divided in two spatially separated locations. Each location is populated with a continuum of agents of unit mass, who live for two periods. Agents receive an endowment $\omega_{1}$ of 
the consumption good when young and $\omega_{2}$ when old. Members of the initial old generation are endowed with an amount on money $M_{0}$ and derive utility from consumption. Goods are perishable, cannot be moved between islands and cannot be stored. Monetary policy is conducted as in the models above. The CB chooses the rate of growth of the money supply to maximize social welfare, which is given by the expected utility of a member of generation $t \geq 1$. Also as above, the Friedman rule is associated with the money growth rate that equalizes the consumption of movers and nonmovers.

With probability $\pi$ a young agent must move to the other island. The mass of agent who must move is assumed to be $\pi$ as well. Movers cannot receive their endowment when old; however, they can exchange claims on their endowment for money. As in the model of section 2, banks will arise to insure agents against the risk of relocation. In the absence of a storage technology, the CB need not be concerned with productive efficiency in setting the optimal monetary policy.

Agents born at date $t \geq 1$ value consumption according to

$$
u\left(c_{t}, c_{t}^{\prime}\right)=\frac{\left(c_{t}\right)^{1-\rho}}{1-\rho}+\beta \frac{\left(c_{t}^{\prime}\right)^{1-\rho}}{1-\rho}, \quad \rho, \beta \in(0,1)
$$

where $c_{t}$ denotes consumption when young, and $c_{t}^{\prime}$ denotes consumption when old. These agents face the following budget constraint

$$
m_{t}+c_{t} \leq \omega_{1}-\tau \text {. }
$$

The money they have acquired, $m_{t}$, as well as the claims on their future endowment, are deposited in a bank. After they have learned they must re- 
locate, movers go to the bank and withdraw cash. ${ }^{6}$ Movers face the following constraint,

$$
\pi c_{t}^{\prime m} \leq \frac{m_{t}}{\sigma}
$$

while nonmovers face the constraint

$$
(1-\pi) c_{t}^{\prime n} \leq \omega_{2}
$$

The expected utility of a member of generation $t \geq 1$ is thus

$$
U(t)=\frac{\left(\omega_{1}-\tau-m_{t}\right)^{1-\rho}}{1-\rho}+\frac{\beta}{1-\rho}\left\{\pi^{\rho}\left[\frac{m_{t}}{\sigma}\right]^{1-\rho}+(1-\pi)^{\rho}\left[\omega_{2}\right]^{1-\rho}\right\} .
$$

The following proposition is proved in the appendix.

Proposition 3 The Friedman rule does not maximize social welfare in this economy.

Thus we can state the next proposition.

Proposition 4 A trade-off between productive efficiency and risk sharing is not necessary for the Friedman rule not to maximize social welfare.

\subsection{CB lending}

This section shows neither financial intermediation nor a trade-off between efficiency and risk sharing is sufficient for the Friedman rule not to maximize social welfare. This result is established by showing that in the economy of section 2 , the Friedman rule maximizes welfare if the CB can make loans. ${ }^{7}$

\footnotetext{
${ }^{6}$ We focus on the case where liquidity is scarce, so movers receive all the money held by the bank.

${ }^{7}$ For example, as suggested by Smith (2002 a) we can think of the CB as operating a discount window or engaging in open market operations. We consider a CB which makes loan at a gross rate of interest of 1 .
} 
Proposition 5 The Friedman rule is optimal in this economy if the $C B$ can make loans.

Proof. First, note that since the CB makes loans, banks do not need to sell goods to old agents in order to acquire cash. Hence, they can invest all their resources in the storage technology. Since $\sigma$ does not influence the transfer to the initial old, the $\mathrm{CB}$ chooses the money growth rate that provides full risk sharing; i.e., $\sigma=1 / x$.

Several features of this equilibrium are worth noting. First, the money held by the initial old will be worthless. Second, money does not circulate between generations. The CB lends money to banks at date $t$ and retires all the money at date $t+1$. Third, in all but the first period, the price level is indeterminate. However, the consumption enjoyed by all generations is the same for any strictly positive, finite price level.

Our result differs from Smith (2002a) because we do not require that the money held by the initial old have the same value as the money lent by the $\mathrm{CB}$ in subsequent periods. If the $\mathrm{CB}$ does not make loans, decreasing the rate of growth of the money supply has two effects. First, it increases the value of money, and thus the consumption of the initial old. This transfer from current and future generations to the initial old reduces the value of the CB's objective function. Second, it reduces the difference in consumption between movers and nonmovers which, everything else being equal, increases the value of the CB's objective function. When the CB makes loans, the first effect disappears, while the second remains, so the Friedman rule maximizes social welfare. 
Finally, it is interesting to note that if the CB did care about the initial old, it could guarantee the members of this generation some consumption by limiting the amount it lends to banks. Even in that case, however, the Friedman rule would be optimal since the size of the transfer to the initial old can be made independent of the rate of growth of money by adjusting the $\mathrm{CB}$ lending limit.

To conclude this section we state the following proposition.

Proposition 6 Neither financial intermediation nor a trade-off between efficiency and risk sharing is sufficient for the Friedman rule not to maximize social welfare.

\section{The role of intergenerational transfers}

This section shows that whether or not the Friedman rule maximizes social welfare depends on the possibility of implementing intergenerational transfers. If such transfers can be implemented, the Friedman rule maximizes social welfare.

First we prove lemma 7.

Lemma 7 Any feasible allocation such that $\sigma>1 / x$ is Pareto dominated by a feasible allocation with $\sigma=1 / x$.

Proof. Consider a feasible allocation such that $\sigma>1 / x$. Call this the initial allocation. By reducing the money growth rate, there is an increase in the reserve-to-deposit ratio of banks, and thus the amount of goods available to 
the initial old. However, with bequests it is possible to offset this exactly. Call the allocation thus obtained the alternative allocation. Now compare the welfare provided to each generation by the initial and the alternative allocation. Members of the initial old generation are indifferent as they receive exactly the same amount of consumption with each allocation. Members of all other generations have the exact same expected consumption. However, they are facing less risk because as $\sigma \rightarrow 1 / x$, the consumption of movers approaches the consumption of nonmovers. Since these agents are risk averse, they have strictly higher utility under the alternative allocation.

This lemma does not depend on the choice of a specific welfare function.

One way to think about lemma 7 is to consider a planner who can choose the rate of growth of the money supply, how much good is invested in the storage technology, and how much is sold to the old. This planner is thus more limited than is usually assumed as he is unable to allocate goods directly to movers and nonmovers. Lemma 7 states that such a limited planner would always choose the Friedman rule.

\subsection{Allowing mutually beneficial arrangements}

In light of lemma 7 , one might ask whether there are mutually beneficial arrangements which would make the Friedman rule maximize social welfare in the economy of section $2 .{ }^{8}$ We show such arrangements exist and can be enforced without any additional assumption.

Assume agents alive in a given period can vote to modify the rules under

\footnotetext{
${ }^{8}$ We are indebted to Jordan Rappaport for pointing this out to us.
} 
which the CB operates. The set of such rules is called the CB's charter. In this model, it specifies $\sigma$ and $\tau$, as well as, possibly, other lump-sum taxes or transfers. The following proposition shows the $\mathrm{CB}$ will be required to implement the Friedman rule.

Proposition 8 Any charter will require the CB to follow the Friedman rule.

Proof. Suppose it is not the case, then it is possible to write a new charter according to which the CB follows the Friedman rule, and old agents make transfers to young agents (this is enforceable since the CB can make lump-sum taxes/transfers). According to lemma 7, this new charter can be designed to be unanimously accepted.

Knowing the exact form the $\mathrm{CB}$ charter takes would require us to fully specify the game agents play. In particular, the bargaining power of each generation and their threat points, who has agenda setting power, would need to be determined. However, regardless of how the surplus is distributed, the Friedman rule will be chosen. A tax/transfer scheme can be set up to partially offset the transfer from the current and future generations to the initial old. ${ }^{9}$ Hence, unless such mutually beneficial arrangements are ruled out, the Friedman rule is optimal in this class of models.

\subsection{Bequests}

To further illustrate the role of intergenerational transfers, we show the Friedman rule maximizes social welfare when agents care about their offsprings,

\footnotetext{
${ }^{9}$ See Bhattacharya, Haslag, and Russell (2003) for a particular mechanism design of a $\mathrm{CB}$ regime that meets the conditions of the charter described in Proposition 8.
} 
as in Freeman (1993).

We consider the same economy as in section 2, but now assume that each agent cares about the utility of his/her unique offspring. Because of this form of altruism, we consider a different social welfare function. As in Freeman (1993), the natural choice of such a function in this environment is the utility of a member of the initial old generation. It follows from lemma 7, that the Friedman rule is optimal in this environment. This is stated in the following proposition.

Proposition 9 The Friedman rule is optimal in this economy if agents care about their offsprings.

Proof. If the initial old does not want to make a bequest, the Friedman rule maximizes the value of a unit money and thus the consumption of the initial old. If bequests are positive, the Friedman rule maximizes the utility of an agent's offspring, for any given level of bequest.

Once again, the key is the role played by inter-generational transfers. Since the money held by members of the initial old generation is valued, there is a transfer from the current and future generations to the initial old. The increase in the value of money which accompanies a decrease in the rate of growth of the money supply increases the value of that transfer. In the models of sections 2, 3.1 and 3.2 , the $\mathrm{CB}$ has an incentive to limit the size of that transfer, because it does not have a way to offset it, and it does not care about the utility of the initial old. Bequests redistribute goods from the initial old generation to the current and future generations in a way that offsets the effect of a higher value of money. 


\section{Summary and conclusion}

We have shown that overlapping generations models in which money is valued because of spatial separation and limited communication do not provide a convincing case against the Friedman rule. In these models, financial intermediation or a trade-off between productive efficiency and risk sharing are neither necessary nor sufficient for the Friedman rule not to maximize social welfare. Instead, we show the result owes to the intergenerational transfer that arises because money is valued. We show this in three different settings: one in which the welfare of the initial old is explicitly taken into account and there is a bequest motive, another in which mutually beneficial arrangements between generations are allowed, and finally, in a setting in which the CB can make inter-period loans. In all three environments the Friedman rule is optimal. Our view is that more research is needed to make a theoretical case against the Friedman rule. 


\section{Appendix}

\section{Proof of Proposition 1}

Let $\Omega(\sigma):=\omega-\tau=\frac{\omega-g}{1-\frac{\sigma-1}{\sigma} \gamma(\sigma)}$, and $\Gamma(\sigma):=\pi^{\rho}\left[\frac{\gamma}{\sigma}\right]^{1-\rho}+(1-\pi)^{\rho}[(1-\gamma) x]^{1-\rho}$, where $g$ denotes government purchases of goods and services. Throughout our analysis, we assume that $g=0$. Welfare is given by

$$
W(\sigma):=\frac{\Omega(\sigma)^{1-\rho}}{1-\rho} \Gamma(\sigma) .
$$

The expression for the banks' reserve to deposit ratio is obtained by taking the derivative of equation 5 with respect to $\gamma$ and setting it to zero.

$$
\gamma(\sigma)=\left\{1+\left(\frac{1-\pi}{\pi}\right)[\sigma x]^{\frac{1-\rho}{\rho}}\right\}^{-1}
$$

The expression for $\gamma^{\prime}(\sigma)$ is given by

$$
\gamma^{\prime}(\sigma)=\frac{1-\rho}{\rho} \frac{\gamma(\sigma)}{\sigma}(\gamma(\sigma)-1),
$$

First we show $\Gamma^{\prime}(\sigma)<0$. Recall,

$$
\Gamma(\sigma)=\pi^{\rho}\left[\frac{\gamma(\sigma)}{\sigma}\right]^{1-\rho}+(1-\pi)^{\rho}[(1-\gamma(\sigma)) x]^{1-\rho}
$$

Thus,

$$
\begin{aligned}
\Gamma^{\prime}(\sigma)= & \pi^{\rho}(1-\rho)\left[\frac{\gamma^{\prime}(\sigma)}{\sigma}\left(\frac{\gamma(\sigma)}{\sigma}\right)^{-\rho}-\frac{1}{\sigma}\left(\frac{\gamma(\sigma)}{\sigma}\right)^{1-\rho}\right] \\
& -(1-\rho) \gamma^{\prime}(\sigma)\left(\frac{1-\pi}{1-\gamma(\sigma)}\right)^{\rho} x^{1-\rho} \\
& =-\pi^{\rho}(1-\rho) \frac{1}{\sigma}\left(\frac{\gamma(\sigma)}{\sigma}\right)^{1-\rho}<0
\end{aligned}
$$

Since $\pi^{\rho} \frac{1}{\sigma}\left(\frac{\gamma(\sigma)}{\sigma}\right)^{-\rho}-\left(\frac{1-\pi}{1-\gamma(\sigma)}\right)^{\rho} x^{1-\rho}=0$. 
Next, we show $W(\sigma)$ reaches a maximum at $\sigma=1$. Note $W^{\prime}(\sigma)>0$ if and only if

$$
\begin{gathered}
\Omega^{\prime}(\sigma) \frac{\sigma}{\Omega(\sigma)}>-\frac{1}{1-\rho} \Gamma^{\prime}(\sigma) \frac{\sigma}{\Gamma(\sigma)} . \\
\Omega^{\prime}(\sigma)=\frac{(\omega-g)\left[\sigma-\gamma(\sigma)(\sigma-1)-\sigma+\sigma \gamma(\sigma)+\sigma \gamma^{\prime}(\sigma)(\sigma-1)\right]}{[\sigma-\gamma(\sigma)(\sigma-1)]^{2}} \\
=\Omega(\sigma)\left[\frac{1}{\sigma}-\frac{1-\gamma(\sigma)+\gamma^{\prime}(\sigma)(\sigma-1)}{\sigma-\gamma(\sigma)(\sigma-1)}\right],
\end{gathered}
$$

which implies

$$
\Omega^{\prime}(\sigma) \frac{\sigma}{\Omega(\sigma)}=\frac{\gamma(\sigma)+\sigma \gamma^{\prime}(\sigma)(\sigma-1)}{\sigma-\gamma(\sigma)(\sigma-1)} .
$$

Substituting for $\gamma^{\prime}(\sigma)$, we get

$$
\Omega^{\prime}(\sigma) \frac{\sigma}{\Omega(\sigma)}=\frac{\gamma(\sigma)\left[1+\frac{1-\rho}{\rho}(\sigma-1)(\gamma(\sigma)-1)\right]}{\sigma-\gamma(\sigma)(\sigma-1)} .
$$

We also need the expression for $\Gamma^{\prime}(\sigma) \frac{\sigma}{\Gamma(\sigma)}\left(-\frac{1}{1-\rho}\right)$. It is given by

$$
\Gamma^{\prime}(\sigma) \frac{\sigma}{\Gamma(\sigma)}\left(-\frac{1}{1-\rho}\right)=\frac{\pi^{\rho}\left(\frac{\gamma(\sigma)}{\sigma}\right)^{1-\rho}}{\pi^{\rho}\left(\frac{\gamma(\sigma)}{\sigma}\right)^{1-\rho}+(1-\pi)^{\rho}(1-\gamma(\sigma))^{1-\rho} x^{1-\rho}}=\gamma(\sigma),
$$

since $\pi^{\rho} \frac{1}{\sigma}\left(\frac{\gamma(\sigma)}{\sigma}\right)^{-\rho}-\left(\frac{1-\pi}{1-\gamma(\sigma)}\right)^{\rho} x^{1-\rho}=0$. It follows that $W(\sigma)^{\prime}>0$ if and only if

$$
\frac{1+(1-\rho) \rho(\sigma-1)(\gamma(\sigma)-1)}{\sigma-\gamma(\sigma)(\sigma-1)}>1 .
$$

This last expression is equivalent to $\sigma>1$. Thus, $W(\sigma)$ is maximized at $\sigma=1$

Note that the value of $\sigma$ which maximizes $W(\sigma)$ does not depend on $x$. The above result holds if $x$ is a random variable rather than a known 
constant. Assume $\bar{x} \geq x \geq \underline{x}>0$. Let $F$ denote the cumulative distribution function of $x$ and $f$ the associated probability distribution function. Assume $\int_{\underline{x}}^{\bar{x}} x f(x) d x=\hat{x}>1$. In the above expressions, $x^{1-\rho}$ is replaced by $\int_{\underline{x}}^{\bar{x}} x^{1-\rho} f(x) d x$. Nothing else is modified and the result goes through.

\section{Proof of Proposition 3}

To find the optimal amount of real balances, $m_{t}$, agents choose to acquire, we take the partial derivative of $U(t)$ with respect to $m_{t}$ and set it equal to zero.

$$
m_{t}=\left(\omega_{1}-\tau\right) \frac{\pi \beta^{\frac{1}{\rho}} \sigma^{\frac{\rho-1}{\rho}}}{1+\pi \beta^{\frac{1}{\rho}} \sigma^{\frac{\rho-1}{\rho}}} .
$$

The CB then chooses $\sigma$ to maximize $U(t)$.

$$
\frac{\partial U(t)}{\partial \sigma}=\left(\omega_{1}-\tau-m_{t}\right)^{-\rho}\left(\frac{\partial \tau}{\partial \sigma}-\frac{\partial m_{t}}{\partial \sigma}\right)+\beta \pi^{\rho}\left\{\frac{1}{\sigma^{1-\rho} m_{t}^{\rho}} \frac{\partial m_{t}}{\partial \sigma}-\frac{m_{t}^{1-\rho}}{\sigma^{2-\rho}}\right\},
$$

where

$$
\begin{aligned}
\frac{\partial m_{t}}{\partial \sigma} & =\frac{\rho-1}{\rho} \frac{1}{\sigma} \frac{m_{t}\left(\omega_{1}-\tau\right)}{1+\pi \beta^{\frac{1}{\rho}} \sigma^{\frac{\rho-1}{\rho}}} \\
\frac{\partial \tau}{\partial \sigma} & =\frac{1}{\sigma^{2}} m_{t} .
\end{aligned}
$$

We can thus write

$$
\begin{aligned}
\frac{\partial U(t)}{\partial \sigma}= & \left(\omega_{1}-\tau-m_{t}\right)^{-\rho}\left[\frac{m_{t}}{\sigma^{2}}-\frac{\rho-1}{\rho} \frac{1}{\sigma} \frac{m_{t}\left(\omega_{1}-\tau\right)}{1+\pi \beta^{\frac{1}{\rho}} \sigma^{\frac{\rho-1}{\rho}}}\right] \\
& +\beta \pi^{\sigma}\left[\left(\frac{m_{t}}{\sigma}\right)^{1-\rho} \frac{\rho-1}{\rho} \frac{1}{\sigma} \frac{\left(\omega_{1}-\tau\right)}{1+\pi \beta^{\frac{1}{\rho}} \sigma^{\frac{\rho-1}{\rho}}}-\frac{1}{\sigma}\left(\frac{m_{t}}{\sigma}\right)^{1-\rho}\right] \\
= & m_{t}^{1-\rho}\left(\frac{\beta \pi^{\rho}}{\sigma^{1-\rho}}\right) \frac{1}{\sigma}\left[\frac{1}{\sigma}-1\right] .
\end{aligned}
$$

It is clear from this last equation that $U(t)$ is maximized at $\sigma=1$. However, this will in general not correspond to the Friedman rule. The 
Friedman rule, which equates the consumption of movers and nonmovers, requires $\sigma \omega_{2}=m_{t}$. It can be shown that this implies

$$
\sigma=\left[\frac{\omega_{1}-\omega_{2}}{\omega_{2}}\right] \pi^{\rho} \beta
$$

Hence, there exists a $\sigma>0$ which corresponds to the Friedman rule whenever $\omega_{1}>\omega_{2}$. This value of $\sigma$ is equal to 1 only for a set of measure zero in the parameter space. 


\section{References}

Bencivenga, Valerie R. and Bruce D. Smith, 1991. "Financial intermediation and endogenous growth," Review of Economic Studies 58, 195-209.

Bhattacharya, Joydeep, Mark Guzman, Elizabeth Huybens and Bruce, D. Smith, 1997. "Monetary, fiscal and bank regulatory policy in a simple monetary growth model," International Economic Review 38(2), 321-351.

Bhattacharya, Joydeep, Joseph H. Haslag and Steven Russell, 2003. "When and why is the Friedman rule optimal?" manuscript.

Chari, V.V., Lawrence J. Christiano, and Patrick J. Kehoe, 1996. "Optimality of the Friedman rule in economies with distorting taxes," Journal of Monetary Economics 37, 203-223.

Correia, Isabel and Pedro Teles, 1996. "Is the Friedman rule optimal when money is an intermediate good?" Journal of Monetary Economics 38, 223244.

Freeman, Scott, 1993. "Resolving differences over the optimal quantity of money," Journal of Money, Credit, and Banking 25, 801-811.

Friedman, Milton, 1969. "The Optimum quantity of money," in The Optimum Quantity of Money and Other Essays. Chicago: Aldine. 
Kimbrough, Kent P., 1986. "The optimum quantity of money rule in the theory of public finance," Journal of Monetary Economics 18, 277-284.

Paal, Beatrix and and Bruce D. Smith, 2000. "The sub-optimality of the Friedman rule and the optimum quantity of money," manuscript.

Schreft, Stacey and Bruce D. Smith, 2002. "The conduct of monetary policy with a shrinking stock of government debt," Journal of Money, Credit, and Banking 34(3) part 2, 848-82.

Schreft, Stacey and Bruce D. Smith, 2003. "The social value of risk-free government debt," working paper 02-03, Federal Reserve Bank of Kansas City.

Smith, Bruce D., 2002a. "Monetary policy, banking crises, and the Friedman rule," American Economic Review papers and proceedings 92, 128-134.

Smith, Bruce D., 2002b. "Taking intermediation seriously," manuscript.

Townsend, Robert M., 1980. "Models of money with spatially separated agents," in Models of Monetary Economics, J. Kareken and N. Wallace, eds. Minneapolis: Federal Reserve Bank of Minneapolis Press, 265-303. 